\title{
Clinicopathological analysis of CD44 and CD24 expression in invasive breast cancer
}

\author{
MIN HYE JANG ${ }^{1}$, HYUN JONG KANG ${ }^{2}$, KI SEOK JANG ${ }^{3}$, SEUNG SAM PAIK ${ }^{3}$ and WAN SEOP KIM ${ }^{4}$ \\ ${ }^{1}$ Department of Pathology, Yeungnam University Hospital, Daegu 42415; ${ }^{2}$ Department of Surgery, \\ Konkuk University Hospital, Chungju 27376; ${ }^{3}$ Department of Pathology, Hanyang University College of Medicine, \\ Seoul 04763; ${ }^{4}$ Department of Pathology, Konkuk University School of Medicine, Seoul 05030, Republic of Korea
}

Received May 11, 2015; Accepted June 16, 2016

DOI: $10.3892 / 01.2016 .4987$

\begin{abstract}
A subpopulation of breast cancer cells with cluster of differentiation (CD)44-positive and CD24-negative expression has been reported to have stem cell properties and to have a higher tumorigenic capacity than other cells. However, the clinicopathological characteristics of this subpopulation are not fully understood. In this study, we aimed to identify the correlations between the expression of CD44 and CD24 and clinicopathological parameters and overall survival. We studied specimens from 262 patients with invasive breast cancer. Immunohistochemical staining for CD44 and CD24 was performed using tissue microarrays. The clinicopathological factors were evaluated from the patients' medical records. In correlation analysis, CD44 expression was significantly associated with human epidermal growth factor receptor 2 (HER2)-negative status ( $\mathrm{P}<0.001)$. Conversely, CD24 expression was significantly associated with HER2-positive status $(\mathrm{P}<0.001)$. CD44 and CD24 expression did not demonstrate any correlation with the age, tumor size, axillary lymph node metastasis status, tumor stage, histological grade, estrogen receptor status and progesterone receptor status of patients. Upon survival analysis, there was no statistical difference in overall survival according to the expression of CD44 and CD24. The results from this study suggest that CD44 and CD24 are clinically significant markers associated with breast tumorigenesis, but not sufficient factors in determining the prognosis of invasive breast cancer.
\end{abstract}

\section{Introduction}

It was previously demonstrated that in solid tumors only a minority of cancer cells have the capacity to proliferate

Correspondence to: Dr Wan Seop Kim, Department of Pathology, Konkuk University School of Medicine, 4-12 Hwayang-dong, Gwangjin-gu, Seoul 05030, Republic of Korea

E-mail: wskim@kuh.ac.kr

Key words: breast cancer, CD44 /CD24-, HER2, stem cell property, clinicopathological characteristics extensively and form new tumors. The so-called cancer stem cells are defined by common properties: the capability of self-renewal and the ability of differentiation $(1,2)$. For cancer to develop, a population of continuously proliferating cells must arise (3). These have to be transformed and survive by altering the pathway of cancer cell differentiation and proliferation over the lifetime of the host. This new implication of the cancer stem cell model has been suggested to account for potential differences in drug sensitivity and may identify individual risk of metastasis. An improved understanding of cancer stem cells could improve our ability to regulate target therapy (1).

In 2003, Al-Hajj et al suggested the ability to distinguish tumorigenic (tumor-initiating) cells from non-tumorigenic cancer cells based on the expression of cell surface markers including cluster of differentiation (CD)24 and CD44 (4). This group proposed that $\mathrm{CD} 44^{+} / \mathrm{CD} 24^{- \text {low }}$ breast cancer cells were capable of forming a small number of tumors in immunocompromised mice. The cells gave rise to phenotypically diverse cancer cells, which they may be similar to stem cells.

The CD44 protein is involved in multiple distinct cellular functions, including proliferation, adhesion and migration (5). It has been associated with stem cells in normal and malignant breast tissues (6). CD24 protein is considered to be a molecule having the functions of adhesion, development and progression $(7,8)$.

However, the molecular characteristics and clinical significance of CD44 and CD24 are unclear. In this study, we assessed the clinical implications of CD44 and CD24 as markers of breast cancer stem cells by identifying their correlation with clinicopathological factors of invasive breast cancer.

\section{Materials and methods}

Patients and clinicopathological data. The present study was approved by the institutional review board (IRB) of Konkuk University Hospital (Seoul, Korea; IRB number KUH1210036), and patient's informed consent was waived.

A total of 262 patients with invasive breast cancer underwent surgery at Hanyang University Medical Center, Seoul, Korea, from 1989 to 1999 . None of the patients had a history of previous therapies with anticancer drugs or radiation therapy. All patients received routine chemotherapy or 
endocrine therapy following surgery. In the present study, we retrospectively analyzed the clinical and pathological data of the patients.

The evaluation variables were age, tumor size, axillary lymph node metastasis status, tumor stage, histological grade, estrogen receptor (ER) status, progesterone receptor (PR) status and human epidermal growth factor receptor 2 (HER2) status. We also analyzed the survival time of patients. The median follow-up time was 91.9 months.

The baseline characteristics of the patients are summarized in Table I. Tumor size and axillary nodal status were categorized according to the tumor-node-metastasis (TNM) system criteria from the American Joint Committee on Cancer classification. The tumor histological grade was classified as 1, 2 or 3 according to the guidance of Elston and Ellis (9).

Tissue microarray construction. For tissue microarray (TMA) construction, hematoxylin and eosin-stained sections of each tumor were examined. Representative areas of tumors were selected and marked on the corresponding paraffin block. The TMAs were assembled using a tissue-array instrument (AccuMac Arrayer, ISU ABXIS Co. Ltd, Seoul, Korea) consisting of thin-walled stainless steel punches and stylets used to empty and transfer the needle content. The selected area in the corresponding paraffin block was punched out and embedded in microarray blocks. Two 3-mm cores of the selected area in the corresponding paraffin block from each case were arrayed.

Immunohistochemical assessment of hormone receptor and HER2. Table II lists the primary antibodies against ER (Lab Vision/Neomarkers, Fremont, CA, USA), PR (Lab Vision/ Neomarkers), HER2 (Dako, Glostrup, Denmark), CD44 (Lab Vision/Neomarkers) and CD24 (Lab Vision/Neomarkers), their dilutions, and the pretreatment conditions. Bound secondary antibiotics were visualized by standard avidin-biotin-peroxidase techniques using diaminobenzidine as a chromogen. ER and PR status were determined by immunohistochemistry using ASCO/CAP guidelines (10). In general, tumors with $>1 \%$ positively stained tumor cells were classified as positive for ER and PR.

HER 2 status was also determined by immunohistochemistry. HER2-positive tumors were defined as 3+ and HER2-negative tumors were defined as 0 or $1+$, using the American Society of Clinical Oncology/College of American Pathologists (ASCO/CAP) guidelines as the criteria for immunohistochemical staining (11). For tumors with equivocal immunoreactivity $(2+)$, we performed silver in situ hybridization (SISH) of the HER2 gene to determine an accurate HER2 status.

Silver in situ hybridization for assessment of HER2 status. For the determination of HER2 status in 2+ cases of HER2 immunohistochemistry, HER2 SISH was performed on an automated Ventana Benchmark instrument (Roche Diagnostics GmbH, Mannheim, Germany), according to the manufacturer's instructions for the INFORM HER2 Dual ISH DNA Probe cocktail. The evaluation of HER2 gene amplification status was performed in a blind manner using the updated 2013 ASCO/CAP guidelines (11). HER2/CEP17
Table I. Patient characteristics.

\begin{tabular}{|c|c|}
\hline Characteristics & No. of patients ( \\
\hline All patients & 262 \\
\hline \multicolumn{2}{|l|}{ Age, years } \\
\hline$<50$ & $156(59.5)$ \\
\hline$\geq 50$ & $106(40.5)$ \\
\hline \multicolumn{2}{|l|}{ Tumor size, $\mathrm{cm}$} \\
\hline$\leq 2$ & $115(43.9)$ \\
\hline$>2-5$ & $127(48.5)$ \\
\hline$>5$ & $20(7.6)$ \\
\hline \multicolumn{2}{|c|}{ Lymph node metastasis } \\
\hline Yes & $129(49.2)$ \\
\hline No & $133(50.8)$ \\
\hline \multicolumn{2}{|l|}{ Stage } \\
\hline I & $52(19.8)$ \\
\hline II & $150(57.3)$ \\
\hline III & $60(22.9)$ \\
\hline \multicolumn{2}{|c|}{ Histological grade } \\
\hline 1 & $25(11.4)$ \\
\hline 2 & $116(52.7)$ \\
\hline 3 & $79(35.9)$ \\
\hline \multicolumn{2}{|c|}{ Estrogen receptor ${ }^{b}$} \\
\hline Positive & $144(55.6)$ \\
\hline Negative & $115(44.4)$ \\
\hline \multicolumn{2}{|c|}{ Progesterone receptor ${ }^{b}$} \\
\hline Positive & $142(54.8)$ \\
\hline Negative & $117(45.2)$ \\
\hline \multicolumn{2}{|l|}{$\mathrm{HER}^{\mathrm{c}}$} \\
\hline Positive & $73(28.5)$ \\
\hline Negative & $183(71.5)$ \\
\hline
\end{tabular}

${ }^{\mathrm{a}}$ Evaluation of histological grade was performed only in 220 cases. 'Immunohistochemical staining of estrogen and progesterone receptors was performed in only 259 cases due to tissue loss of tissue microarray blocks. 'HER 2 status was assessed in only 256 cases due to tissue loss or inappropriate hybridization . HER2, human epidermal growth factor receptor 2 .

SISH signals were selected and 20 non-overlapping nuclei were analyzed. Amplification was defined by first examining the HER2/CEP17 ratio followed by the average HER2 copy number. A ratio of $\geq 2.0$ indicated amplification of the gene regardless of the average HER 2 copy number. A ratio of $<2.0$ with an average HER 2 copy number between 4.0 and $<6.0$ was defined as equivocal. For the equivocal cases, signals from 20 further tumor nuclei were counted in a second target area and a new ratio was calculated. A ratio of $<2.0$ with an average HER 2 copy number $<4.0$ was defined as having no amplification.

Immunohistochemical assessment of CD44 and CD24. Four-micrometer sections were made from the formalin-fixed, paraffin-embedded blocks, which were then deparaffinized in 
Table II. Antibodies and antigen retrieval techniques used.

\begin{tabular}{llllr}
\hline Antibody & Clone & Source & Antigen retrieval & Dilution \\
\hline ER & Sp1 & Lab Vision/Neomarkers & Benchmark XT protocol & $1: 600$ \\
PR & Sp2 & Lab Vision/Neomarkers & Benchmark XT protocol & $1: 600$ \\
HER2 & Polyclonal & Dako & Benchmark XT protocol & $1: 100$ \\
CD44 & 156-3C11 & Lab Vision/Neomarkers & Citrate/autoclave & $1: 300$ \\
CD24 & SN3 & Lab Vision/Neomarkers & Citrate/autoclave & $1: 100$ \\
\hline
\end{tabular}

ER, estrogen receptor; PR, progesterone receptor; HER2, human epidermal growth factor receptor 2; CD, cluster of differentiation.
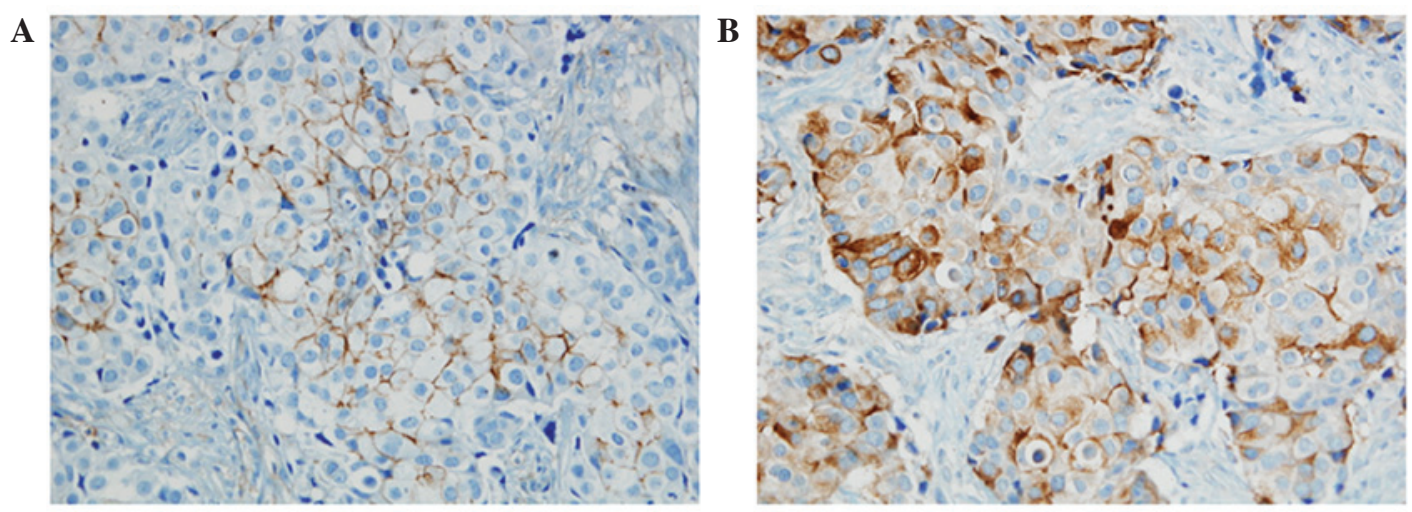

Figure 1. Immunohistochemical staining pattern of invasive breast cancer. (A) CD44-positive expression; (B) CD24-positive expression. Magnification, x400. $\mathrm{CD}$, cluster of differentiation.

xylene and rehydrated in a graded series of alcohol solutions. For antigen retrieval, paraffin tissue sections were cooked with $10 \mathrm{mM}$ sodium citrate buffer, $\mathrm{pH}$ 6.0, at a sub-boiling temperature for $15 \mathrm{~min}$ and cooled for $20 \mathrm{~min}$ at room temperature. The sections were washed twice with Tris-buffered saline for $10 \mathrm{~min}$.

The antibody incubations were carried out at room temperature for $1 \mathrm{~h}$. CD44 and CD24 were detected with standard avidin-biotin-peroxidase techniques using diaminobenzidine as the chromogen. Afterwards, the slides were briefly counterstained with hematoxylin, dehydrated and mounted.

Immunostained samples were evaluated by two pathologists. The expression of CD44 and CD24 was graded in terms of the percentage of cytoplasmic membrane staining in each block as well as the intensity of staining. However, there is no common cut-off value on the patterns of staining. In this study, the grade was designated according to the following criteria: 0 , no staining; 1 , staining in less than $50 \%$; and 2 , staining in more than $50 \%$ of tumor cells. The grades were classified into two groups: (-), grade $0 ;(+)$, grade 1 and grade 2 (Fig. 1).

Statistical analysis. The Statistical Package for the Social Sciences (IBM SPSS, Armonk, NY, USA) for Windows version 19.0 was used for all the analyses. The Pearson's $\chi^{2}$ test was used to examine statistically significant differences between the expression of CD44 and CD24 and clinicopathological parameters. $\mathrm{P}<0.05$ was considered to indicate a statistically significant difference. The overall survival was estimated using the Kaplan-Meier analysis.

\section{Results}

Clinicopathological characteristics. All 262 cases had invasive breast cancer. The median age of the patients was 47 years (range, 26-78). A total of 156 cases (59.5\%) were younger than 50 years and 106 cases $(40.5 \%)$ were 50 years or older. A total of 115 cases $(43.9 \%)$ had a tumor size of $2 \mathrm{~cm}$ or less, 127 cases $(48.5 \%)$ had tumors between 2 and $5 \mathrm{~cm}$, and 20 cases $(7.6 \%)$ had a tumor size greater than $5 \mathrm{~cm}$. A total of 133 cases $(50.8 \%)$ demonstrated negative axillary lymph node metastasis and 129 cases (49.2\%) demonstrated positive axillary lymph node metastasis. A total of 52 cases (19.8\%) were stage I, 150 cases $(57.3 \%)$ were stage II, and 60 cases $(22.9 \%)$ were stage III (Table I).

Immunohistochemistry. Among the 262 cases, only 259 were assessed for expression of ER and PR. A total of 144 cases (55.6\%) were ER-positive and 115 cases (44.4\%) were ER-negative. A total of 142 cases $(54.8 \%)$ were PR-positive and 117 cases $(45.2 \%)$ were PR-negative. HER2 status was evaluated in 256 cases. A total of 73 cases $(28.5 \%)$ demonstrated HER2 positivity and 183 cases $(71.5 \%)$ were HER2-negative (Table I). Among the 262 cases, 259 cases were assessed for the expression of CD44 and CD24 protein. A total of 165 cases $(63.7 \%)$ were CD44 protein-positive, whereas 94 cases $(36.3 \%)$ were CD44 protein-negative. A total of 188 cases $(71.7 \%)$ 
Table III. Correlation between expression of CD44, CD24 and clinicopathological variables.

\begin{tabular}{|c|c|c|c|c|c|c|}
\hline \multirow[b]{2}{*}{ Characteristics } & \multicolumn{3}{|c|}{ CD44 } & \multicolumn{3}{|c|}{$\mathrm{CD} 24$} \\
\hline & Positive (\%) & Negative (\%) & P-value & Positive (\%) & Negative (\%) & P-value \\
\hline All cases & $165(63.7)$ & $94(36.3)$ & & 188 (71.7) & $74(28.3)$ & \\
\hline Age, years & & & 0.276 & & & 0.057 \\
\hline$<50$ & $101(61.2)$ & $51(54.3)$ & & $107(56.9)$ & $49(66.2)$ & \\
\hline$\geq 50$ & $64(38.8)$ & $43(45.7)$ & & $81(43.1)$ & $25(33.8)$ & \\
\hline Tumor size, $\mathrm{cm}$ & & & 0.056 & & & 0.854 \\
\hline$\leq 2$ & 79 (47.9) & $35(36.6)$ & & $84(44.7)$ & $31(41.9)$ & \\
\hline$>2$ & $78(47.3)$ & $49(52.7)$ & & $89(47.3)$ & $38(51.4)$ & \\
\hline$>5$ & $8(4.8)$ & $10(10.7)$ & & $15(8.0)$ & $5(6.7)$ & \\
\hline LN metastasis & & & 0.413 & & & 0.137 \\
\hline Yes & $86(52.1)$ & $44(46.8)$ & & $98(52.1)$ & $31(41.9)$ & \\
\hline No & 79 (47.9) & $50(53.2)$ & & $90(47.9)$ & $43(58.1)$ & \\
\hline Stage & & & 0.393 & & & 0.746 \\
\hline $\mathrm{I}$ & $36(21.8)$ & $18(18.0)$ & & 37 (19.7) & $15(20.3)$ & \\
\hline II & $90(54.5)$ & $52(57.0)$ & & $107(56.9)$ & $43(58.1)$ & \\
\hline III & $39(23.7)$ & $24(25.8)$ & & $44(23.4)$ & $16(21.6)$ & \\
\hline Histological grade ${ }^{a}$ & & & 0.181 & & & 0.256 \\
\hline 1 & $20(14.7)$ & $5(6.3)$ & & $15(9.7)$ & $10(15.4)$ & \\
\hline 2 & $68(50.0)$ & $43(54.4)$ & & $82(52.9)$ & $34(52.3)$ & \\
\hline 3 & $48(35.3)$ & $31(39.3)$ & & $58(37.4)$ & $21(32.3)$ & \\
\hline Estrogen receptor ${ }^{\mathrm{b}}$ & & & 0.857 & & & 0.661 \\
\hline Positive & $93(56.7)$ & $51(55.4)$ & & $105(56.5)$ & $39(53.4)$ & \\
\hline Negative & $72(43.3)$ & $41(44.6)$ & & $81(43.5)$ & $34(46.6)$ & \\
\hline Progesterone receptor ${ }^{\mathrm{b}}$ & & & 0.556 & & & 0.095 \\
\hline Positive & $90(54.9)$ & $54(58.7)$ & & $108(58.1)$ & $34(46.6)$ & \\
\hline Negative & $74(45.1)$ & $38(41.3)$ & & 78 (41.9) & $39(53.4)$ & \\
\hline $\mathrm{HER}^{\mathrm{c}}$ & & & $<0.001$ & & & $<0.001$ \\
\hline Positive & $33(20.5)$ & $39(42.4)$ & & $65(35.3)$ & $8(11.1)$ & \\
\hline Negative & $128(79.5)$ & $53(57.6)$ & & $119(64.7)$ & $64(88.9)$ & \\
\hline
\end{tabular}

${ }^{a}$ Evaluation of histological grade was performed only in 220 cases. ${ }^{\mathrm{b}}$ Immunohistochemical staining of estrogen and progesterone receptors was

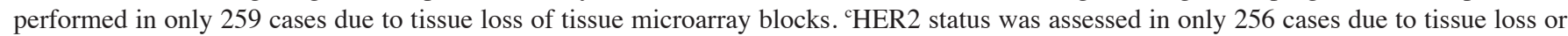
inappropriate hybridization. LN, lymph node; HER2, human epidermal growth factor receptor 2; CD, cluster of differentiation.

were CD24 protein-positive, whereas 74 cases (28.3\%) were CD24 protein-negative (Table III).

Correlation between CD44 and CD24 and clinicopathological variables. Table III shows the correlations between the expression of CD44 and CD24 and clinicopathological factors. HER2-negative status was associated with positive CD44, and HER2-positive status was associated with positive $\mathrm{CD} 24$ ( $\mathrm{P}<0.001$ and $\mathrm{P}<0.001$, respectively). There was no correlation between the expression of CD44 and CD24 and other clinicopathological factors, including age, tumor size, axillary lymph node metastasis status, stage, histological grade or hormonal status.

The median follow-up time was 91.9 months. The Kaplan-Meier method was used to identify the prognostic significance of CD44 and CD24. There was no significant difference between overall survival and the expression of CD44 or CD24 ( $\mathrm{P}=0.437, \mathrm{P}=0.976$, respectively).

\section{Discussion}

Cancer stem cells have the common ability to self-renew, differentiate, acquire drug resistance, survive and migrate. Breast cancer stem cells are a small population of cells which have classic features of cancer stem cells, and become tumorigenic cells through the accumulation of mutations (12). The initial identification of breast cancer stem cells was based on a combination of CD44 and CD24; in particular, the $\mathrm{CD} 44^{+} / \mathrm{CD} 24^{-/ \text {low }}$ phenotype has been reported to have stem cell properties (4).

In contrast, other studies have revealed that the prevalence of $\mathrm{CD} 44^{+} / \mathrm{CD} 24^{-/ \text {low }}$ cells was not significantly associated with 
breast tumor progression or patient survival $(13,14)$. Further studies demonstrated that the CD $44^{+} / \mathrm{CD} 24^{- \text {-low }}$ cells were transit progenitors; however, they did not determine either the molecular subtype or clinical parameters in breast cancer (15).

CD44 is a type I transmembrane glycoprotein receptor that binds primarily to the extracellular glycosaminoglycan hyaluronan. This protein is also known as a cellular adhesion molecule and has been linked to diverse effects including cellular adhesion, migration and invasion, which are significant in cancer progression $(16,17)$.

CD24 is a glycosylphosphatidylinositol-anchored membrane protein that is also known as a cell surface molecule, and represents small membrane microdomains endowed with cell adhesion and cell signaling properties $(18,19)$.

The aim of this study was to investigate the clinical significance of CD44 and CD24 expression in paraffin-embedded sections of breast cancer. We examined the correlation between expression of the markers and clinicopathological parameters.

According to Horiguchi et al, higher CD44 expression was significantly correlated with smaller tumor size, negative axillary lymph node metastasis and lower stage (20). In this study, we did not observe any correlation between CD44 expression and clinicopathological factors, with the exception of HER2 status. Our data revealed that the expression of CD44 was significantly correlated with HER2-negative status $(\mathrm{P}<0.001)$. HER2-negative is part of the basal phenotype. Bànkfalvi et al indicated that myoepithelial cells expressed CD44 in normal breast epithelium, and that this is implicated in the early stage of breast carcinogenesis (21). Herrera-Gayol et al observed that CD44 expression was involved in two of the three steps of the invasive cascade and could not be confidently used as a reliable prognostic indicator (22). Sanchez et al revealed a deregulation in the CD44 expression pattern in malignant tumors, but did not identify a correlation between this deregulation and clinicopathological factors (23). Conversely, Bànkfalvi et al observed that increased levels of CD44 expression were correlated with poor prognosis and metastatic involvement of the axillary lymph nodes in breast cancer (21). Looi et al revealed that CD44 played a role in the progression of breast cancer (24).

According to Horiguchi et al, higher CD24 expression was significantly correlated with larger tumor size, positive axillary lymph node metastasis and higher stage (20). In this study, we did not observe a correlation between CD24 expression and clinicopathological factors, with the exception of HER2 status. Our data revealed that the expression of CD24 was significantly correlated with HER2-positive status $(\mathrm{P}<0.001)$. The HER2-positive tumor is generally considered an aggressive form of breast cancer. It has been associated with rapid tumor growth through angiogenesis and invasion in breast tumorigenesis. Honeth et al indicated that HER2-positive groups highly expressed CD24 (25). Baumann et al revealed that CD 24 expression increased tumor cell metastasis in vivo, proliferation and spreading, and induced cell motility and invasion (26). Athanassiadou et al revealed that CD24 expression was correlated with adverse prognostic parameters, including increased stage, tumor grade 3, positive lymph nodes and increased tumor size (27). Conversely, Schindelmann et al observed that $\mathrm{CD} 24$ was significantly downregulated in invasive cell lines, and this downregulation might be associated with a more aggressive behavior of the tumor (28).
In conclusion, our results demonstrate that CD44 expression is significantly correlated with HER2-negative status in invasive breast cancer cells. This finding suggests that CD44 is correlated with tumorigenesis in HER2-negative breast cancer. Conversely, CD24 expression is significantly correlated with HER2-positive status. This finding suggests that CD24 is associated with the aggressive phenotype of breast cancer cells. However, there is no difference in clinical outcome and survival with respect to CD44 and CD24 expression. Therefore, we may conclude that CD44 and CD24 are markers associated with tumorigenesis in breast cancer, but not sufficient factors to determine the prognosis of invasive breast cancer.

\section{Acknowledgements}

This study was supported by grants from the Korea Breast Cancer Foundation.

\section{References}

1. Al-Hajj M, Becker MW, Wicha M, Weissman I and Clarke MF: Therapeutic implications of cancer stem cells. Curr Opin Genet Dev 14: 43-47, 2004.

2. Smalley M and Ashworth A: Stem cells and breast cancer: a field in transit. Nat Rev Cancer 3: 832-844, 2003.

3. Clarke MF and Fuller M: Stem cells and cancer: two faces of eve. Cell 124: 1111-1115, 2006.

4. Al-Hajj M, Wicha MS, Benito-Hernandez A, Morrison SJ and Clarke MF: Prospective identification of tumorigenic breast cancer cells. Proc Natl Acad Sci USA 100: 3983-3988, 2003.

5. Ponta H, Sherman L and Herrlich PA: CD44: from adhesion molecules to signalling regulators. Nat Rev Mol Cell Biol 4: 33-45, 2003.

6. Hebbard L, Steffen A, Zawadzki V, Fieber C, Howells N, Moll J, Ponta H, Hofmann M and Sleeman J: CD44 expression and regulation during mammary gland development and function. J Cell Sci 113: 2619-2630, 2000.

7. Aigner S, Sthoeger ZM, Fogel M, Weber E, Zarn J, Ruppert M, Zeller Y, Vestweber D, Stahel R, Sammar M and Altevogt P: CD24, a mucin-type glycoprotein, is a ligand for P-selectin on human tumor cells. Blood 89: 3385-3395, 1997.

8. Kristiansen G, Winzer KJ, Mayordomo E, Bellach J, Schlüns K, Denkert C, Dahl E, Pilarsky C, Altevogt P, Guski H and Dietel M: CD24 expression is a new prognostic marker in breast cancer. Clin Cancer Res 9: 4906-4913, 2003.

9. Elston CW and Ellis IO: Pathological prognostic factors in breast cancer. I. The value of histological grade in breast cancer: experience from a large study with long-term follow-up. Histopathology 19: 403-410, 1991.

10. Hammond ME, Hayes DF, Dowsett M, Allred DC, Hagerty KL, Badve S, Fitzgibbons PL, Francis G, Goldstein NS, Hayes M, et al: American Society of Clinical Oncology/College of American Pathologists guideline recommendations for immunohistochemical testing of estrogen and progesterone receptors in breast cancer. Arch Pathol Lab Med 134: 907-922, 2010.

11. Wolff AC, Hammond ME, Hicks DG, Dowsett M, McShane LM, Allison KH, Allred DC, Bartlett JM, Bilous M, Fitzgibbons P, et al: Recommendations for human epidermal growth factor receptor 2 testing in breast cancer: American Society of Clinical Oncology/College of American Pathologists clinical practice guideline update. J Clin Oncol 31: 3997-4013, 2013.

12. Reya T, Morrison SJ, Clarke MF and Weissman IL: Stem cells, cancer, and cancer stem cells. Nature 414: 105-111, 2001.

13. Abraham BK, Fritz P, McClellan M, Hauptvogel P, Athelogou M and Brauch H: Prevalence of CD44+/CD24-/low cells in breast cancer may not be associated with clinical outcome but may favor distant metastasis. Clin Cancer Res 11: 1154-1159, 2005.

14. Mylona E, Giannopoulou I, Fasomytakis E, Nomikos A, Magkou C, Bakarakos P and Nakopoulou L: The clinicopathologic and prognostic significance of CD44+/CD24(-/low) and $\mathrm{CD} 44^{-} / \mathrm{CD} 24^{+}$tumor cells in invasive breast carcinomas. Hum Pathol 39: 1096-1102, 2008. 
15. Lü X, Xu K, Lü H, Yin Y, Ma C, Liu Y, Li H and Suo Z CD44(+)/CD24(-) cells are transit progenitors and do not determine the molecular subtypes and clinical parameters in breast carcinomas. Ultrastruct Pathol 35: 72-78, 2011.

16. Iida N and Bourguignon LY: New CD44 splice variants associated with human breast cancers. J Cell Physiol 162: 127-133, 1995.

17. Naor D, Sionov RV and Ish-Shalom D: CD44: Structure, function, and association with the malignant process. Adv Cancer Res 71: 241-319, 1997.

18. Henniker AJ: CD24. J Biol Regul Homeost Agents 15: 182-184, 2001.

19. Fogel M, Friederichs J, Zeller Y, Husar M, Smirnov A, Roitman L, Altevogt $\mathrm{P}$ and Sthoeger ZM: CD24 is a marker for human breast carcinoma. Cancer Lett 143: 87-94, 1999.

20. Horiguchi K, Toi M, Horiguchi S, Sugimoto M, Naito Y, Hayashi Y, Ueno T, Ohno S, Funata N, Kuroi K, et al: Predictive value of CD24 and CD44 for neoadjuvant chemotherapy response and prognosis in primary breast cancer patients. J Med Dent Sci 57: 165-175, 2010.

21. Bànkfalvi A, Terpe HJ, Breukelmann D, Bier B, Rempe D, Pschadka G, Krech R and Böcker W: Gains and losses of CD44 expression during breast carcinogenesis and tumour progression. Histopathology 33: 107-116, 1998.
22. Herrera-Gayol A and Jothy S: Adhesion proteins in the biology of breast cancer: contribution of CD44. Exp Mol Pathol 66: 149-156, 1999.

23. Sanchez Lockhart M, Hajos SE, Basilio FM, Mongini C and Alvarez E: Splice variant expression of CD44 in patients with breast and ovarian cancer. Oncol Rep 8: 145-151, 2001.

24. Looi LM, Cheah PL, Zhao W, Ng MH and Yip CH: CD44 expression and axillary lymph node metastasis in infiltrating ductal carcinoma of the breast. Malays J Pathol 28: 83-86, 2006.

25. Honeth G, Bendahl PO, Ringnér M, Saal LH, Gruvberger-Saal SK, Lövgren K, Grabau D, Fernö M, Borg A and Hegardt C: The CD44+/CD24- phenotype is enriched in basal-like breast tumors. Breast Cancer Res 10: R53, 2008.

26. Baumann P,Cremers N, Kroese F, Orend G, Chiquet-Ehrismann R, Uede T, Yagita H and Sleeman JP: CD24 expression causes the acquisition of multiple cellular properties associated with tumor growth and metastasis. Cancer Res 65: 10783-10793, 2005.

27. Athanassiadou P, Grapsa D, Gonidi M, Athanassiadou AM, Tsipis A and Patsouris E: CD24 expression has a prognostic impact in breast carcinoma. Pathol Res Pract 205: 524-533, 2009.

28. Schindelmann S, Windisch J, Grundmann R, Kreienberg R, Zeillinger R and Deissler H: Expression profiling of mammary carcinoma cell lines: Correlation of in vitro invasiveness with expression of CD24. Tumour Biol 23: 139-145, 2002. 